\title{
Quanto Vale o Show? Impactos Econômicos dos Investimentos da Copa do Mundo 2014 no Brasil
}

\author{
Edson Paulo Domingues* \\ Admir Antonio Betarelli Junior**

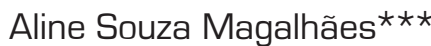

\begin{abstract}
Resumo
O objetivo deste trabalho é projetar os impactos econômicos, nacionais e regionais dos investimentos de infraestrutura e estádios para a Copa do Mundo de 2014. Consideram-se os investimentos em reforma/ construção de infraestrutura esportiva (estádios) e infraestrutura urbana divulgados pelo Ministério do Esporte no início de 2010. Por meio de simulações com um modelo de equilíbrio geral, são projetados os impactos das fases de construção e operação desses investimentos, com atenção especial às fontes de financiamento (público, privado e BNDES). Os resultados apontam para um crescimento adicional médio de $1,2 \%$ no PIB das cidades-sede e a geração do equivalente a 158 mil empregos. A análise dos resultados indica, entretanto, que o impacto positivo desses investimentos depende da capacidade de financiamento privado e das necessidades de realocação do gasto público. Quanto maior a utilização de recursos públicos no financiamento dos investimentos da Copa 2014, menor seu impacto econômico.
\end{abstract}

\section{Palavras-Chave}

eventos esportivos, modelos de economia regional, equilíbrio geral computável

\section{Predicting the Economic Impact of the 2014 FIFA World Cup in Brazil}

\begin{abstract}
This paper aims to predict the economic impacts of 2014 FIFA World Cup in the Brazilian economy, states and host cities. We consider the investments in renovation/construction of sports infrastructure (stadiums) and urban infrastructure published recently by the Ministry of Sports. The impacts of construction and operation of those investments are projected through simulations with a computable general equilibrium model, with special attention to funding options (public, private and BNDES).
\end{abstract}

\section{Keywords}

sporting events, regional modeling, computable general equilibrium

\section{JEL Classification}

C68, D58, H54

+ Artigo recebido em julho de 2010 e aceito para publicação em março de 2011.

* Professor Adjunto, Bolsista de Produtividade em Pesquisa (CNPq) e do Programa Pesquisador

Mineiro IV (Fapemig) - E-mail: epdomin@cedeplar.ufmg.br

** Doutorando em Economia - Email: admirbet@cedeplar.ufmg.br

*** Doutorando em Economia - Email: alinesm@ cedeplar.ufmg.br

Endereço para contato: Todos os autores vinculados ao CEDEPLAR-UFMG - Av. Antônio Carlos, 6627 UFMG/FACE - CEP 31270-901 Belo Horizonte, Minas Gerais. 


\section{Introdução}

A promoção de grandes eventos esportivos tem sido uma estratégia de diversos países para a atração de investimentos e de atenção internacional. Os benefícios econômicos destes eventos retratam um argumento utilizado para justificar o esforço e o gasto público para sediar tais eventos. Em 2009 o Brasil, especificamente a cidade do Rio de Janeiro, foi escolhido como sede dos Jogos Olímpicos de 2016. Um amplo estudo do impacto econômico desse evento foi divulgado pelo Comitê Organizador da candidatura brasileira, e os números divulgados ressaltaram os impactos econômicos da realização dos jogos na cidade e no país. Nesse estudo estima-se, por exemplo, que o impacto econômico dos Jogos Olímpicos e Paraolímpicos sobre o PIB (Produto Interno Bruto) do Brasil será de R 22 bilhões até 2016, enquanto que no período de 2017 a 2027, atingirá R 27 bilhões (Secretaria da Comunicação Social da Presidência da República, 2009). Haddad \& Haddad (2010) estimaram os impactos das Olimpíadas de 2016 no Rio de Janeiro. Segundo o estudo, considerando a injeção de US \$14,4 bilhões de dólares para a realização do evento, o efeito gerador verificado equivale a 4,26 (a uma taxa de desconto de 3\%). Isto significa que para cada dólar investido, outros US $\$ 3,26$ seriam gerados até 2027 , resultando em um impacto agregado na economia brasileira de US\$ 51,1 bilhões de dólares a valores de 2008.

A análise do impacto regional e setorial dos investimentos mostra, também, que os investimentos são suficientemente dimensionados de forma a reestruturar a economia da Região Metropolitana do Rio de Janeiro (RMRJ). Todos os indicadores econômicos da RMRJ (produtividade, massa salarial, receita com impostos) destacam novas oportunidades para a população do estado, assim como para o país como um todo (HADDAD \& HADDAD, 2010).

A Copa do Mundo de 2014 (Copa-2014) representa outro grande evento esportivo programado para o Brasil. Na sua preparação, uma série de obras de infraestrutura, reformas e construção de estádios estão sendo programadas. Em meados de 2009, as 12 cidades-sede da Copa, que abrigarão jogos da competição, foram escolhidas: Rio de Janeiro (RJ), São Paulo (SP), Belo Horizonte (MG), Porto Alegre (RS), Brasília (DF), Cuiabá (MT), Curitiba (PR), Fortaleza (CE), Manaus (AM), Natal $(\mathrm{RN})$, Recife (PE) e Salvador (BA). Além das 12 cidades escolhidas, participaram da disputa Rio Branco (AC), Belém (PA), Maceió (AL), Goiânia (GO), Florianópolis (SC) e Campo Grande (MS).

É provável que o Brasil ganhe ampla visibilidade com a promoção dos mega-eventos esportivos agendados; contudo, os benefícios econômicos que tais eventos trarão para o país são difíceis de estimar, pois envolvem obras de infraestrutura urbana, reformas/construção de estádios, fluxos turísticos, investimentos privados (rede 
hoteleira, por exemplo) e divulgação internacional do país. Os organizadores geralmente alegam que eventos como a Copa do Mundo geram estímulos para os negócios domésticos (e.g. restaurantes, hotéis e outros negócios) e, portanto, benefícios econômicos maiores que os custos (NOLL e ZIMBALIST, 1997). O Comitê Organizador da Olimpíada de Atlanta estimou um impulso de \$5,1 bilhões na economia e um aumento de 77.000 empregos (BARCLAY, 2009).

A metodologia mais frequentemente utilizada nos estudos de impactos de eventos esportivos é a análise de insumo-produto, que pode estimar os efeitos diretos e indiretos desses eventos na economia. Alguns autores consideram, entretanto, que os efeitos multiplicadores obtidos superestimam os efeitos reais, pois a metodologia utiliza hipóteses de oferta ilimitada de fatores de produção, não lida com os efeitos de substituição nem custos de oportunidade. Além disso, haja vista que os multiplicadores estão baseados numa estrutura de produção vigente da economia, não capta as mudanças que a realização do evento esportivo pode provocar nas relações produtivas. Existem também casos em que o método de insumo-produto não é capaz de captar certos vazamentos durante o evento esportivo (e.g. lucros ganhos pelo evento pode não fluir para a economia local, mas para os acionistas estrangeiros) (BARCLAY, 2009; MADDEN, 2006; PORTER, 1999).

Matheson (2002) aponta que diversos estudos geralmente superestimam o impacto econômico sobre a economia local; Porter (1999) enfatiza que os benefícios previstos pelos gastos públicos nunca se materializam. Trabalhos como de Coates e Humphreys (1999) e Noll e Zimbalist (1997) não encontraram correlação entre a construção de estádios esportivos e desenvolvimento econômico regional. Brenke e Wagner (2006), ao analisarem os efeitos da Copa do Mundo em 2006 na Alemanha, constataram que as expectativas estavam sobrevalorizadas, de forma que os empregos adicionais eram somente temporários e os custos de infraestrutura e promoção da Copa-2006 foram significativos. Eles concluíram que os principais beneficiários dos eventos foram a FIFA e a German Football Association (DFB). Pillay e Bass (2008) apontam que, ao contrário do que se espera na Copa da África do Sul, os empregos gerados pela construção de estádios são temporários e após o evento esportivo o desemprego urbano poderá subir.

Swinnen e Vandemoortele (2008) destacam algumas diferenças entre a Alemanha e a África do Sul como sedes da Copa do Mundo. A primeira diferença repousa no custo de investimentos em infraestrutura. Enquanto na África do Sul os investimentos requeridos são altos para construir novos estádios, na Alemanha, que já detinha a maior parte dos estádios, os investimentos limitaram-se a adequações dos estádios em conformidade com as normas da FIFA. Os investimentos em infraestrutura urbana serão maiores na África do Sul. Uma segunda diferença recai sobre 
o custo do capital e custo do trabalho. O custo do capital é maior em países em desenvolvimento, ou seja, dinheiro gasto no evento representa dinheiro não gasto em outras áreas, tal como o sistema de saúde. No entanto, nesses países os salários são relativamente baixos, possibilitando certa redução nos custos operacionais e de infraestrutura.

Outro aspecto diz respeito ao financiamento dos investimentos requeridos pelos eventos com recursos públicos, o que pode gerar redução de outras despesas ou elevação da dívida pública. Somente em 2006, após 30 anos da realização dos Jogos Olímpicos, a cidade de Montreal conseguiu sanar uma dívida de R $\$ 2,8$ bilhões (GOLDEN GOAL, 2010). Nesses termos, a principal questão posta é se o financiamento dos mega-eventos com recursos públicos promove um retorno mais eficiente quando comparado com os retornos de outras formas de investimentos, como, por exemplo, no sistema de saúde e de educação (SWINNEN e VANDEMOORTELE, 2008). Conforme Barclay (2009), a construção de novos estádios pode aumentar a atividade econômica, mas também pode elevar os custos de oportunidade para o setor público e, geralmente, tem por consequência a redução de outros serviços públicos, um maior empréstimo do governo ou impostos mais altos.

Aliado ao aspecto do endividamento público, a falta de planejamento após o megaevento esportivo pode provocar a subutilização das infraestruturas construídas e, com isso, produzir alto custo de manutenção. Para os países em desenvolvimento existem grandes riscos na promoção de um mega-evento, haja vista que os estádios construídos podem se tornar "elefantes brancos" (BARCLAY, 2009). Quatro anos após os Jogos Olímpicos de Sidney, o Estado precisou assumir os custos de manutenção das arenas e estádios em virtude da quebra da empresa responsável pela administração dessas infraestruturas (GOLDEN GOAL, 2010). Por ano, o Governo da Grécia despende aproximadamente R $\$ 202$ milhões em custo de manutenção da infraestrutura construída para os jogos. Por outro lado, os mega-eventos esportivos podem representar um catalisador de aceleração do processo de investimento em áreas cruciais que já deveriam ter ocorrido.

Nesse aspecto se concentram, particularmente, os investimentos em infraestrutura urbana. Em adição aos investimentos na construção de arenas, Barcelona (1992) e Seul (1988) usaram os jogos para regenerar inteiramente suas infraestruturas urbanas (BARCLAY, 2009). Uma infraestrutura deficiente, que frequentemente restringe o crescimento econômico de uma região, quando revitalizada em virtude de Copa do Mundo, pode produzir uma redução de custo e fornecer um impulso de produtividade à própria economia (SWINNEN e VANDEMOORTELE, 2008). 
O objetivo deste artigo é estimar alguns dos impactos da Copa 2014 no Brasil, com detalhamento de suas repercussões estaduais e municipais. Para isso, simulações com um modelo de equilíbrio geral computável (EGC) são efetuadas a partir dos dados oficiais de investimentos para a Copa. Além desta seção introdutória, este trabalho organiza-se em mais quatro seções: a próxima seção apresenta os investimentos previstos para a Copa 2014 em cada cidade-sede; a seção 3 aborda as hipóteses na operacionalização do modelo; os resultados das simulações são apresentados e discutidos na seção 4; a quinta seção tece as considerações finais.

\section{Os Investimentos para a Copa 2014}

O Ministério do Esporte divulgou no início de fevereiro de 2010 os investimentos em infraestrutura para a Copa-2014, no que diz respeito à mobilidade urbana (avenidas, corredores metropolitanos, acessos a aeroportos, urbanização no entorno dos estádios) e reformas e construção de estádios. Segundo esses dados, quase a totalidade dos investimentos ( $\mathrm{R} \$ 10,1$ bilhões) será financiada por órgãos e esferas públicas (Tabela 1). Tal fato aponta para a inexistência de recursos provindos da "iniciativa privada" ou de Parcerias Público-Privada (PPP). O governo federal argumenta que o BNDES (Banco Nacional do Desenvolvimento Econômico e Social) buscará parte dos recursos em empréstimos feitos junto às condições e operações de mercado, ${ }^{1}$ o que pode ser considerado um financiamento privado (BASTOS e COBOS, 2010).

\section{TABELA 1 - Investimentos Previstos em Obras para a Copa-2014 (R\$ milhões)}

\begin{tabular}{|c|c|c|c|c|c|c|}
\hline \multirow[b]{2}{*}{ Fonte de Recursos } & \multicolumn{4}{|c|}{ Obras } & \multirow[b]{2}{*}{ Total } & \multirow[b]{2}{*}{ Part. (\%) } \\
\hline & $\begin{array}{c}\text { Infraestrutura } \\
\text { Urbana }\end{array}$ & Part. (\%) & Estádio & Part. (\%) & & \\
\hline BNDES & 1499,0 & 14,8 & 3427,6 & 64,8 & 4926,6 & 32,0 \\
\hline Financiamento Caixa & 6422,3 & 63,5 & 0,0 & 0,0 & 6422,3 & 41,7 \\
\hline Governo Distrital & 0,0 & 0,0 & 340,0 & 6,4 & 340,0 & 2,2 \\
\hline Governo Estadual & 1740,6 & 17,2 & 1156,4 & 21,9 & 2897,0 & 18,8 \\
\hline Governo Municipal & 452,0 & 4,5 & 34,1 & 0,6 & 486,1 & 3,2 \\
\hline Clube Atlético Paranaense & 0,0 & 0,0 & 113,0 & 2,1 & 113,0 & 0,7 \\
\hline Esporte Clube Internacional & 0,0 & 0,0 & 130,0 & 2,5 & 130,0 & 0,8 \\
\hline São Paulo Futebol Clube & 0,0 & 0,0 & 85,0 & 1,6 & 85,0 & 0,6 \\
\hline$\overline{\text { Total }}$ & 10113,9 & 100,0 & 5286,1 & 100,0 & 15400,0 & 100,0 \\
\hline
\end{tabular}

Fonte: Ministério do Esporte.

1 Dentre as fontes de recursos na composição do funding do BNDES estão, por exemplo, as captações no Mercado, através de operações compromissadas com o Banco do Brasil utilizando parte dos títulos públicos adquiridos junto ao TN; e captação através de Depósitos Interfinanceiros, junto a instituições financeiras privadas nacionais. Em 30 de junho de 2009, essas fontes atingiram um montante de $\mathrm{R} \$ 27,2$ bilhões, equivalente a $8,8 \%$ das fontes de recursos totais, ou R \$ 309, 018 bilhões (BNDES (2009), vide Anexo 1). 
A reforma ou construção dos estádios para a Copa-2014 parece ser a primeira iniciativa no cronograma de preparação das cidades para as Competições. Dos doze estádios-sede da Copa de 2014, três são de propriedade privada (Complexo Esportivo Curitiba, Morumbi e Beira Rio), correspondendo a 6,2\% do total de investimentos previsto em estádios ( $\mathrm{R} \$ 5,2$ bilhões). Conforme a Tabela 1, o BNDES será o principal financiador das obras em estádios, cerca de $\mathrm{R} \$ 3,4$ bilhões $(64,8 \%$ do total). Aliás, desse total, $\mathrm{R} \$ 25$ milhões serão concedidos sob forma de crédito ao Clube Atlético Paranaense, e R\$ 150 milhões ao São Paulo Futebol Clube. ${ }^{2}$ Dessa maneira, enquanto as esferas do Governo destacam-se no financiamento de infraestrutura urbana, o BNDES fomentará, sobretudo, os investimentos em estádios. Em ambos os casos, os investimentos dependem de condições regionais específicas, como a articulação das esferas municipais e estaduais de governo, assim como de financiamento ou mecanismos de incentivo/subsídio.

O total dos investimentos previsto em obras de infraestrutura urbana e estádios correspondem a 0,7\% do Produto Interno Bruto (PIB) dos Estados-sede (Tabela 2). Em relação ao total do PIB municipal, o investimento de R $\$ 15,4$ bilhões representa $1,9 \%$ do PIB do conjunto das cidades-sede. Embora o montante de investimentos destinados para as obras na cidade de São Paulo seja proeminente $(20,1 \%$ dos investimentos), tal montante representa somente $0,9 \%$ do PIB da cidade. Por outro lado, os investimentos destinados para a adequação da Copa-2014 em Cuiabá (MT) correspondem $11,3 \%$ do seu PIB.

2 Posteriormente, o Estádio do Morumbi foi descartado para utilização na Copa 2014, sendo substituído por um novo estádio a ser construído na cidade de São Paulo. Os dados divulgados são de um investimento de $\mathrm{R} \$ 600$ milhões no estádio (www.copa2014.org.br em 16/05/2011), embora existam dúvidas sobre a factibilidade do projeto. 
TABELA 2 - Investimentos Previstos por Cidades-Sede para a Copa-2014

\begin{tabular}{lcccc}
\hline Cidades-Sede & Valor (R\$ milhões) & Part. (\%) & \% PIB Mun. & \% PIB Estadual \\
\hline Manaus (AM) & 1837,80 & 11,93 & 5,34 & 4,37 \\
Fortaleza (CE) & 1031,60 & 6,70 & 4,22 & 2,05 \\
Natal (RN) & 695,00 & 4,51 & 8,66 & 3,03 \\
Recife (PE) & 1168,00 & 7,58 & 5,64 & 1,88 \\
Salvador (BA) & 1131,30 & 7,35 & 4,23 & 1,03 \\
Belo Horizonte (MG) & 1431,60 & 9,30 & 3,75 & 0,59 \\
Rio de Janeiro (RJ) & 1910,00 & 12,40 & 1,37 & 0,64 \\
São Paulo (SP) & 3096,50 & 20,11 & 0,97 & 0,34 \\
Curitiba (PR) & 603,90 & 3,92 & 1,60 & 0,37 \\
Porto Alegre (RS) & 498,60 & 3,24 & 1,49 & 0,28 \\
Cuiabá (MT) & 894,70 & 5,81 & 11,32 & 2,10 \\
Brasília (DF) & 1101,00 & 7,15 & 1,10 & 1,10 \\
\hline Total & 15400,00 & 100,00 & 1,95 & 0,70 \\
\hline
\end{tabular}

Fonte: Ministério do Esporte (2010) e IBGE (PIB de 2007).

Os investimentos previstos na cidade de Fortaleza concentram-se para a reforma do Estádio Castelão (59,8\%), enquanto que em Belo Horizonte as obras com infraestrutura urbana representam juntas $71,5 \%$ do total previsto de investimento em Minas Gerais, com destaque para as Avenidas Antônio Carlos e Pedro I. Em São Paulo, por seu turno, para a Construção do Monotrilho (Linha Ouro), serão despendidos aproximadamente $\mathrm{R} \$ 2,5$ bilhões, sendo o maior montante em todo o Brasil (16,6\%). Com menos destaque, nota-se que a construção do Monotrilho Norte em Manaus também é representativo - cerca de 62,2\% do total amazonense e $7,4 \%$ do total brasileiro. 


\section{TABELA 3 - Investimentos Previstos nas Cidades-Sede da Região Nordestina para Copa-2014}

\begin{tabular}{|c|c|c|c|c|c|c|}
\hline \multirow{2}{*}{ Cidade } & \multirow{2}{*}{ Projeto } & \multirow{2}{*}{$\begin{array}{c}\text { Valor (R\$ } \\
\text { milhões) }\end{array}$} & \multirow{2}{*}{$\begin{array}{l}\text { Part. }(\%) \\
\text { no Estado }\end{array}$} & \multirow{2}{*}{$\begin{array}{l}\text { Part. }(\%) \\
\text { no Brasil }\end{array}$} & \multicolumn{2}{|c|}{ Previsão } \\
\hline & & & & & Início & Fim \\
\hline Manaus & Monotrilho Norte; Eixo Leste Centro & 1143,1 & 62,2 & 7,4 & $\operatorname{mar} / 10$ & $\operatorname{dez} / 13$ \\
\hline Manaus & Demais obras de infraestrutura urbana & 194,7 & 10,6 & 1,3 & $\operatorname{dez} / 11$ & $\operatorname{mar} / 14$ \\
\hline Manaus & Reconstrução do Estádio Vivaldão & 500,0 & 27,2 & 3,2 & $\operatorname{mar} / 10$ & $\operatorname{dez} / 12$ \\
\hline Salvador & Corredor Estruturante: Aeroporto/Acesso Norte & 541,8 & 47,9 & 3,5 & ago/10 & ago/12 \\
\hline Salvador & Reconstrução do Estádio da Fonte Nova & 589,5 & 52,1 & 3,8 & $\operatorname{mar} / 10$ & $\operatorname{dez} / 12$ \\
\hline Fortaleza & VLT: Parangába / Mucuripe & 170,0 & 16,5 & 1,1 & $\mathrm{jan} / 11$ & jun/13 \\
\hline Fortaleza & Demais obras de infraestrutura urbana & 244,4 & 23,7 & 1,6 & $\mathrm{jan} / 11$ & $\operatorname{dez} / 12$ \\
\hline Fortaleza & Reforma do Estádio Castelão & 617,2 & 59,8 & 4,0 & $\operatorname{mar} / 10$ & $\operatorname{dez} / 12$ \\
\hline Brasília & VLT: Linha 1 / Trecho 1 / Aeroporto e outros & 361,0 & 32,8 & 2,3 & $\mathrm{ju} / 10$ & $\operatorname{mar} / 12$ \\
\hline Brasília & Reforma do Estádio Mané Garrincha & 740,0 & 67,2 & 4,8 & $\operatorname{mar} / 10$ & $\operatorname{dez} / 12$ \\
\hline Belo Horizonte & Avenidas Antônio Carlos e Pedro I & 382,3 & 26,7 & 2,5 & $\mathrm{jul} / 10$ & set/12 \\
\hline Belo Horizonte & Demais obras de infraestrutura urbana & 641,0 & 44,8 & 4,2 & jun/10 & out 12 \\
\hline Belo Horizonte & Reforma e Adaptação do Estádio Mineirão & 408,3 & 28,5 & 2,7 & jun $/ 10$ & $\operatorname{dez} / 12$ \\
\hline Cuiabá & Aeroporto, CPA -Leste e Oeste & 307,7 & 34,4 & 2,0 & $\operatorname{dez} / 10$ & $\mathrm{jul} / 12$ \\
\hline Cuiabá & Demais obras de infraestrutura urbana & 147,0 & 16,4 & 1,0 & $\mathrm{jul} / 10$ & $\operatorname{dez} / 11$ \\
\hline Cuiabá & Construção do Estádio José Frageli -Verdão & 440,0 & 49,2 & 2,9 & $\operatorname{mar} / 10$ & $\operatorname{dez} / 12$ \\
\hline Recife & Corredor da Via Mangue & 331,0 & 28,3 & 2,1 & $\mathrm{jul} / 10$ & $\mathrm{ju} / 13$ \\
\hline Recife & Demais obras de infraestrutura urbana & 317,0 & 27,1 & 2,1 & $a b r / 10$ & $\mathrm{mai} / 13$ \\
\hline Recife & Contrução de Novo Estádio "Cidade da Copa" & 520,0 & 44,5 & 3,4 & $\operatorname{mar} / 10$ & $\operatorname{dez} / 12$ \\
\hline Curitiba & Corredor Metropolitano & 125,0 & 20,7 & 0,8 & $a b r / 11$ & $a b r / 13$ \\
\hline Curitiba & Demais obras de infraestrutura urbana & 306,8 & 50,8 & 2,0 & set/10 & $\operatorname{dez} / 12$ \\
\hline Curitiba & Reforma e Ampliação do Complexo Esportivo & 172,1 & 28,5 & 1,1 & $\operatorname{jan} / 13$ & $\mathrm{mai} / 13$ \\
\hline Rio de Janeiro & Corredor T5 -Aeroporto / Penha / Barra & 1310,0 & 68,6 & 8,5 & $\mathrm{mai} / 10$ & $\mathrm{mai} / 13$ \\
\hline Rio de Janeiro & Reforma do Estádio Maracanã & 600,0 & 31,4 & 3,9 & $\mathrm{mar} / 10$ & $\operatorname{dez} / 10$ \\
\hline Natal & Integração Novo Aeroporto; Hotelaria e Via Prudente & 350,4 & 50,4 & 2,3 & jun $/ 10$ & nov/12 \\
\hline Natal & Demais obras de infraestrutura urbana & 10,6 & 1,5 & 0,1 & $\operatorname{dez} / 10$ & $\mathrm{ju} / / 11$ \\
\hline Natal & Construção da Arena das Dunas & 334,0 & 48,1 & 2,2 & $\mathrm{mar} / 10$ & $\operatorname{dez} / 12$ \\
\hline São Paulo & Construção do Monotrilho - Linha Ouro & 2549,0 & 82,3 & 16,6 & $\mathrm{jul} / 10$ & $\operatorname{mar} / 13$ \\
\hline São Paulo & Urbanização do Entorno do Morumbi & 312,5 & 10,1 & 2,0 & set/10 & $\operatorname{dez} / 12$ \\
\hline São Paulo & Reforma do Estádio do Morumbi & 235,0 & 7,6 & 1,5 & $\operatorname{mar} / 10$ & $\operatorname{dez} / 12$ \\
\hline Porto Alegre & Corredor Avenida Tronco & 129,3 & 25,9 & 0,8 & $\operatorname{dez} / 10$ & $\operatorname{dez} / 12$ \\
\hline Porto Alegre & Demais obras de infraestrutura urbana & 239,3 & 48,0 & 1,6 & jun $/ 10$ & $\operatorname{dez} / 12$ \\
\hline Porto Alegre & Reforma do Estádio do Beira Rio & 130,0 & 26,1 & 0,8 & $\mathrm{mar} / 10$ & ago/12 \\
\hline Total & & 15400,0 & - & 100,0 & & \\
\hline
\end{tabular}

Fonte: Elaboração Própria a partir dos Dados do Ministério dos Esportes (2010). ${ }^{3}$

3 Os investimentos em aeroportos não foram incluídos nas estimativas do Ministério dos Esportes, mas tem sido considerados vitais para a realização do evento, sendo relacionados como obras do PAC (Plano de Aceleração do Crescimento). Estudo recente do IPEA (CAMPOS NETO e SOUZA, 2011 ) indicou que as obras relativas a aeroportos para a Copa receberiam do Governo Federal valor de R\$ 5,6 bilhões, aplicados pela INFRAERO em 13 aeroportos de 2011 a 2014. 
De modo geral, nota-se que na grande maioria das cidades-sede os investimentos previstos concentram-se nas obras de infraestrutura urbana (Tabela 3). A grande exceção é Brasília, de forma que os recursos estão projetados, principalmente, para a reforma do Estádio Mané Garrincha (67,2\%). Por outro lado, quando se analisam os prazos das obras, também é constatado que em grande parte deles a previsão para o término está agendada para o final de 2012, ano antecedente da Copa das Confederações FIFA 2013.

Os investimentos previstos permitem projetar alguns dos impactos da Copa-2014 sobre a economia brasileira e para os Estados-sede. As informações possibilitam também simular os impactos distinguindo as diferentes fontes de financiamento dos recursos. É nesse ponto que este artigo irá focar sua atenção, pois as hipóteses de financiamento dos recursos têm papel importante no impacto econômico que se projeta para os investimentos da Copa-2014.

Este trabalho utiliza o modelo de Equilíbrio Geral Computável (EGC) IMAGEM-B (Integrated Multi-Regional Applied General Equilibrium Model - Brazil), desenvolvido no CEDEPLAR-UFMG. Podem-se destacar algumas vantagens dos modelos EGC sobre os modelos de insumo-produto para as finalidades deste estudo. Um modelo EGC trabalha com uma estrutura de interdependência entre os setores da economia (as atividades setoriais estão interligadas), como no modelo tradicional de insumoproduto (I-P). Contudo, enquanto que o modelo I-P exibe uma série de limitações [e.g. coeficiente tecnológico constante (função produção de Leontief), retornos constantes de escala, demanda final definida exogenamente, preços rígidos e oferta perfeitamente elástica], o modelo EGC tem a vantagem de projetar impactos de mudança nos preços relativos. Além disso, o modelo EGC, baseado no paradigma walrasiano (neoclássico), especifica elasticidades de substituição imperfeitas, e o equilíbrio entre demanda e oferta é atingido por preços flexíveis. Nesse sentido, a resposta de todo movimento de realocação de recursos pode ser examinada a partir de choques exógenos que se refletem nos preços relativos (DOMINGUES, 2002; ALMEIDA, 2003; HADDAD, 2004; PEROBELLI, 2004). Além disso, as condições específicas de financiamento dos investimentos da Copa-2014 podem ser levadas em consideração.

\section{Modelo e Simulações}

A análise dos impactos nacionais e regionais dos investimentos da Copa-2014 é feita por meio de simulações com um modelo de Equilíbrio Geral Computável (EGC). O modelo EGC utilizado neste trabalho é o IMAGEM-B. O modelo apresenta uma especificação regional integrada: trabalha explicitamente com os 27 estados 
da federação e também produz resultados para os 5507 municípios. ${ }^{4} \mathrm{O}$ comportamento dos agentes é modelado a nível estadual (regiões endógenas), e os resultados nacionais são agregações dos resultados estaduais. A especificação top-down para municípios permite uma decomposição consistente dos resultados estaduais nesse nível de regionalização. O modelo permite simular políticas geradoras de impactos regionais (carteiras de investimento), políticas tributárias regionais, estudos estruturais e decomposição de cenários macroeconômicos. O IMAGEM-B está especificado para 36 setores de atividade, 4 usuários finais (famílias, investimento, governo e exportações) e importações, para cada um dos 27 estados. A base de dados representa a estrutura produtiva da economia brasileira em 2003, inclusive com os fluxos de comércio de bens e serviços entre os estados. No total, a base de dados do modelo apresenta um conjunto de 541.678 elementos numéricos, entre fluxos e parâmetros. Na sua versão completa o modelo possui 1.237.647 variáveis e 1.076.612 equações; para utilização neste trabalho, o modelo foi condensado de acordo com os objetivos das simulações, o que reduz sua dimensão para cerca de 300.000 variáveis e equações. As simulações com o modelo foram operacionalizadas no software GEMPACK (HARRISON e PEARSON, 2002), por meio da construção de rotinas computacionais específicas. Uma descrição detalhada do modelo encontra-se em Domingues et alii (2009). O Anexo 2 apresenta um resumo da especificação e calibragem do modelo.

Neste artigo foram feitas sete simulações para estimar os impactos econômicos da Copa. As simulações estão dividas de acordo com as fontes de recursos destinadas para a construção da infraestrutura urbana e para os estádios, em cada unidade da federação. Seis simulações correspondem à fase de construção dos investimentos previstos pelo Ministério do Esporte (2010). A sétima simulação procura avaliar os ganhos de produtividade das infraestruturas urbanas em operação. $\mathrm{O}$ prazo oficial de conclusão dos investimentos é 2013/2014 para duas competições: Copa das Confederações FIFA (2013) e Copa do Mundo FIFA (2014).

As simulações foram divididas em duas fases: construção e operação. As hipóteses utilizadas nessas duas simulações seguem o padrão da literatura de Equilíbrio Geral Computável, denominados "curto prazo" e "longo prazo", respectivamente.

\subsection{Fase de Construção (Curto Prazo)}

$\mathrm{Na}$ fase de construção, a oferta de capital e terra é constante, em níveis nacional, regional ou setorial, com exceção apenas para construção civil (i.e. os investimentos po-

4 Os resultados dos 5507 municípios são produzidos numa especificação top-down do modelo. No entanto, no trabalho serão reportadas apenas as variações do PIB e emprego das cidades-sede. 
dem provocar o deslocamento do estoque de capital inter-regionalmente desse setor). A oferta de trabalho ajusta-se endogenamente, em resposta a variações no salário real estadual. Nesse tipo de simulação, geralmente o gasto real do governo é fixo. Contudo, para o caso de estádios com financiamento público, tal variável é endógena, uma vez que deve acomodar as necessidades desse investimento. Dessa maneira, por hipótese admite-se que, para o governo financiar as obras em estádios, é necessário reduzir o seu consumo, visto que sua restrição orçamentária original não previa tais despesas.

Nas simulações usuais da fase de construção, é comum assumir que o consumo real das famílias seja fixo. Entretanto, para o caso das simulações de obras de estádios e de infraestrutura urbana financiados pelo BNDES (com recursos captados no mercado) e dos Clubes de Futebol, tal variável é tomada como endógena para absorver o financiamento desse investimento. Assim, assume-se que as fontes de recursos para esse investimento originam-se das famílias, que para isso diminuem seu consumo corrente. É importante notar que o ajuste endógeno do consumo ocorre em todo o país, não apenas naqueles que recebem os investimentos (Estados-sede). Por fim, enquanto que o salário real regional é fixo, o saldo comercial como proporção do PIB é endógeno. O Quadro 1 descreve as simulações de construção (Iml a Im6) e operação (OP). Nessa última simulação (OP) utiliza um fechamento de "longo prazo" ou operação e suas hipóteses serão apresentadas na subseção seguinte:

\begin{tabular}{cccccc}
\hline Simulação & Etapa & Obra & Financiamento & Recursos & $\begin{array}{c}\text { Compensação } \\
\text { Macro }\end{array}$ \\
\hline Im1 & Construção & Estádio & BNDES & Próprio e externo & - \\
Im2 & Construção & Infra. urbana & BNDES & Próprio e externo & - \\
Im3 & Construção & Estádio & BNDES / Clubes F. & Interno & Cons. das Famílias \\
Im4 & Construção & Infra. urbana & BNDES / Clubes F. & Interno & Cons. das Famílias \\
Im5 & Construção & Estádio & Público & Governos / Caixa & Cons. do Governo \\
Im6 & Construção & Infra. urbana & Público & Governos & - \\
OP & Operação & Infra. urbana & - & - & - \\
\hline
\end{tabular}

Fonte: Elaboração própria a partir dos dados do Mnistério do Esporte.

\section{QUADRO 1 - Sumário das Simulações com o Modelo IMAGEM-B}

Nas obras de estádios e infraestrutura urbana, com financiamento de captações internacionais e recursos próprios do BNDES, não há necessidade de compensação macro (ajuste de consumo das famílias ou do governo). Nas obras de estádios e infraestrutura urbana com financiamento do BNDES (recursos internos) e Clubes, há compensação 
macro pelo ajuste do consumo das famílias. O consumo do governo ajusta-se para os investimentos em estádios financiados pelos governos (Im6).

Nas seis primeiras simulações (Iml a Im6), os choques exógenos originam-se da variação do investimento na fase de construção das obras para a Copa-2014 em cada Estadosede. Essa variação percentual é calculada tendo como base a matriz de investimentos do modelo e os investimentos da Copa (Tabela 4). Os valores dos investimentos foram os divulgados pelo Ministério do Esporte, classificados de acordo com a fonte de financiamento, e deflacionados para o ano-base do banco de dados (2003). A Tabela 4 retrata as seis simulações para cada tipo de investimento e Estado, de acordo com a classificação da Tabela 3.

Nas duas primeiras simulações (Iml e Im2), os valores são oriundos de recursos próprios e captações internacionais (externo) do BNDES. Para segmentar os valores divulgados de financiamento pelo BNDES, utilizou-se uma participação média a partir da composição do funding do BNDES, baseado no seu relatório da Administração no primeiro semestre de 2009 (vide Anexo 2). Essas participações estão divididas entre recursos de origens externas, públicas e privadas. Os recursos externos, que representam 57,2\% do funding do BNDES, englobam os fundos PIS-PASEP, FAT e fontes internacionais. Os recursos públicos compreendem os empréstimos locais, principalmente do Tesouro Nacional feitos pelo BNDES $(32,4 \%$ do total).

\section{TABELA 4 - Investimentos da Copa-2014 em cada Simulação (R\$ milhões de 2003)}

\begin{tabular}{|c|c|c|c|c|c|c|c|c|c|c|c|c|}
\hline \multirow[b]{2}{*}{ Estados } & \multicolumn{2}{|c|}{ Im1 } & \multicolumn{2}{|l|}{ Im2 } & \multicolumn{2}{|l|}{$\operatorname{Im} 3$} & \multicolumn{2}{|c|}{ Im4 } & \multicolumn{2}{|l|}{$\operatorname{lm} 5$} & \multicolumn{2}{|l|}{$\operatorname{lm} 6$} \\
\hline & $\begin{array}{c}\mathrm{R} \$ \\
\text { (milhões) }\end{array}$ & $\begin{array}{l}\text { Var. } \\
(\%)\end{array}$ & $\begin{array}{c}\mathrm{R} \$ \\
\text { (milhões) }\end{array}$ & $\begin{array}{l}\text { Var. } \\
(\%)\end{array}$ & $\begin{array}{c}\mathrm{R} \$ \\
\text { (milhões) }\end{array}$ & $\begin{array}{l}\text { Var. } \\
(\%)\end{array}$ & $\begin{array}{c}\mathrm{R} \$ \\
\text { (milhões) }\end{array}$ & $\begin{array}{l}\text { Var. } \\
(\%)\end{array}$ & $\begin{array}{c}\mathrm{R} \$ \\
\text { (milhões) }\end{array}$ & $\begin{array}{l}\text { Var. } \\
(\%)\end{array}$ & $\begin{array}{c}\mathrm{R} \$ \\
\text { (milhões) }\end{array}$ & $\begin{array}{l}\text { Var. } \\
(\%)\end{array}$ \\
\hline Amazonas & 162,8 & 3,5 & 0,0 & 0,0 & 29,4 & 0,6 & 0,0 & 0,0 & 187,1 & 4,1 & 1014,8 & 22,1 \\
\hline Ceará & 173,7 & 3,9 & 0,0 & 0,0 & 31,3 & 0,7 & 0,0 & 0,0 & 263,2 & 5,9 & 314,3 & 7,0 \\
\hline Rio Grande do Norte & 108,8 & 4,7 & 0,0 & 0,0 & 19,6 & 0,8 & 0,0 & 0,0 & 125,0 & 5,3 & 273,8 & 11,7 \\
\hline Pernambuco & 172,4 & 2,5 & 25,6 & 0,4 & 31,1 & 0,4 & 4,6 & 0,1 & 190,9 & 2,8 & 461,3 & 6,7 \\
\hline Bahia & 173,7 & 1,4 & 0,0 & 0,0 & 31,3 & 0,2 & 0,0 & 0,0 & 242,2 & 1,9 & 411,0 & 3,2 \\
\hline Minas Gerais & 130,3 & 0,5 & 0,0 & 0,0 & 23,5 & 0,1 & 0,0 & 0,0 & 156,0 & 0,6 & 776,2 & 3,1 \\
\hline Rio de Janeiro & 173,7 & 0,5 & 516,7 & 1,4 & 31,3 & 0,1 & 93,2 & 0,3 & 250,1 & 0,7 & 383,8 & 1,1 \\
\hline São Paulo & 65,1 & 0,1 & 108,5 & 0,1 & 76,2 & 0,1 & 19,6 & 0,0 & 36,9 & 0,0 & 2042,5 & 2,2 \\
\hline Paraná & 10,9 & 0,1 & 0,0 & 0,0 & 87,7 & 0,5 & 0,0 & 0,0 & 32,0 & 0,2 & 327,5 & 1,9 \\
\hline Rio Grande do Sul & 0,0 & 0,0 & 0,0 & 0,0 & 98,6 & 0,4 & 0,0 & 0,0 & 0,0 & 0,0 & 279,6 & 1,2 \\
\hline Mato Grosso & 143,3 & 3,6 & 0,0 & 0,0 & 25,8 & 0,7 & 0,0 & 0,0 & 164,6 & 4,1 & 344,9 & 8,7 \\
\hline Distrito Federal & 173,7 & 2,8 & 0,0 & 0,0 & 31,3 & 0,5 & 0,0 & 0,0 & 356,3 & 5,8 & 273,8 & 4,5 \\
\hline Total & 1488,2 & 0,5 & 650,8 & 0,2 & 517,3 & 0,2 & 117,4 & 0,0 & 2004,3 & 0,7 & 6903,7 & 2,5 \\
\hline
\end{tabular}

Fonte: Ministério do Esporte. 
Nas simulações Im3 e Im4, o financiamento dos estádios e infraestrutura urbana são decorrentes dos recursos dos Clubes de Futebol que detém direitos de propriedade de três Estádios (Complexo Esportivo Curitiba, Morumbi e Beira Rio) e operações de mercado do BNDES que auxiliarão a instituição para o financiamento em ambas as obras. Operacionalmente é nesses casos que os choques de investimentos serão proporcionalmente compensados por uma variação no consumo das famílias. $\mathrm{Na}$ quinta simulação ( $\operatorname{Im} 5)$, o financiamento de caráter público para os investimentos nos estádios de futebol corresponde à agregação dos Governos (Distrital, Estadual e Municipal) e da Caixa Federal. Assim, nessa simulação é definido que o consumo do governo se reduz à mesma proporção do choque positivo de investimento. Por fim, a última simulação na fase de construção (Im6) compreende investimentos de infraestrutura urbana, que, por hipótese, já estavam previstos pelo governo e não afetam o seu consumo corrente.

\subsection{Fase de Operação (Longo Prazo)}

A simulação da fase de operação (pós-construção), em que as obras de infraestrutura urbana estarão operando, tem o propósito de capturar impactos de produtividade e redução de custo de produção gerado para a economia. Assim, como em Swinnen e Vandemoortele (2008), admite-se que apenas esse tipo de investimento representa um impulso de produtividade para as economias locais. Isso justifica-se pelo fato de que a melhor mobilidade urbana produzirá reduções de custos, direta e indiretamente, para os setores e famílias e, em consequência, produzirá um ganho potencial de produtividade. Ganhos de produtividade também estimulam o aumento do estoque de capital setorial. Portanto, nessa simulação procura-se captar as características e efeitos dos investimentos sobre a elevação no estoque de capital setorial e na produtividade dos fatores. Destarte, estados mais beneficiados com os investimentos passam a ter uma vantagem relativa no sistema inter-regional, seja via produtividade de fatores ou aumento da participação na produção.

Segundo as hipóteses deste trabalho, os investimentos previstos nos estádios de futebol possuem impactos apenas na fase da sua construção, e não representam efeitos de longo prazo (ou seja, estádios não influem em mudanças de produtividade para setores ou de bem-estar para famílias). Assim, as simulações na fase de operação assumem oferta de capital elástica em todos os setores e estados com taxas de retorno fixas. No mercado de fatores pressupõe-se que o emprego nacional é exógeno, ao passo que o salário real nacional ajusta-se endogenamente. Ademais, há mobilidade interestadual do fator trabalho, movida pelos diferenciais de salário real entre os estados. O investimento nacional, por sua vez, é endógeno, obtido pela soma dos investimentos setoriais estaduais. 
O consumo real das famílias e o gasto real do governo seguem as hipóteses tradicionais do longo prazo. O consumo nominal das famílias segue a variação da renda nominal em cada estado (remuneração dos fatores). O gasto do governo move-se na proporção do crescimento estadual da população (variação do emprego). E considerando as contas externas, o saldo comercial é exógeno como proporção do PIB.

O cálculo dos choques da simulação de operação implica a adoção de uma taxa de retorno para a infraestrutura urbana, de forma a se obter o retorno esperado para o novo capital investido. Este retorno repercute sobre a produtividade dos fatores e reflete condições típicas de projetos de investimento de longo prazo da economia brasileira, definida em 12,9\%, conforme utilizada em Domingues et alii (2009). É esperado que os Estados mais beneficiados sejam aqueles que sediarão a competição.

Além disso, uma maior mobilidade urbana, em virtude da revitalização da infraestrutura rodoviária e aérea, produz impulsos de produtividade e reduções de custos de produção em atividades econômicas mais diretamente afetadas pelos investimentos em infraestrutura urbana.

Dessa forma, em termos setoriais foi calibrado um peso relativamente maior para o transporte rodoviário e aéreo, serviços prestados às famílias e alimentos e bebidas (Tabela 5). ${ }^{5}$ Assim, adotou-se a hipótese de que os choques de produtividade são maiores para os setores que são, provavelmente, os mais diretamente afetados por estes investimentos.

5 Formalmente, o choque de produtividade (aprim) no setor $i$ da região $d$ é determinado por: $\operatorname{aprim}(i, d)=-\frac{\operatorname{SHR}(i, d) \cdot(I N V(d) \cdot R O R)}{\text { PRIM_B(i,d)}}$

$\operatorname{aprim}(i, d)$ : variação de produtividade dos fatores primários, setor i da região d; $S H R(i, d)$ : participação do setor i da região $\mathrm{d}$ no benefício de produtividade; $I N V(d)$ : invetimento do projeto na região d;

ROR: taxa de retorno do investimento;

PRIM_B(i,d): remuneração dos fatores primários do setor i na região d. 
TABELA 5 - Choque de Produtividade da Operação das Infraestruturas Urbanas (Var. \%)*

\begin{tabular}{lccccc}
\hline \multicolumn{1}{c}{ Estados } & $\begin{array}{c}\text { Ind. Alimentícia, } \\
\text { Bebidas,Fumo e } \\
\text { Biocombustíveis }\end{array}$ & $\begin{array}{c}\text { Serviços de } \\
\text { Transporte } \\
\text { rodoviário }\end{array}$ & $\begin{array}{c}\text { Serviços de } \\
\text { Transporte } \\
\text { Aéreo }\end{array}$ & $\begin{array}{c}\text { Serviços } \\
\text { Prestados às } \\
\text { Famílias }\end{array}$ & Demais Setores \\
\hline Amazonas & 6,77 & 6,77 & 6,77 & 6,77 & 2,30 \\
Ceará & 2,19 & 2,19 & 2,19 & 2,19 & 0,74 \\
Rio Grande do Norte & $5,11 \mathrm{~A}$ & 5,11 & 5,11 & 5,11 & 1,73 \\
Pernambuco & 2,17 & 2,17 & 2,17 & 2,17 & 0,73 \\
Bahia & 1,06 & 1,06 & 1,06 & 1,06 & 0,36 \\
Minas Gerais & 1,02 & 1,02 & 1,02 & 1,02 & 0,34 \\
Rio de Janeiro & 1,07 & 1,07 & 1,07 & 1,07 & 0,36 \\
São Paulo & 0,88 & 0,88 & 0,88 & 0,88 & 0,29 \\
Paraná & 0,60 & 0,60 & 0,60 & 0,60 & 0,20 \\
Rio Grande do Sul & 0,42 & 0,42 & 0,42 & 0,42 & 0,14 \\
Mato Grosso & 3,11 & 3,11 & 3,11 & 3,11 & 1,05 \\
Distrito Federal & 1,77 & 1,77 & 1,77 & 1,77 & 0,59 \\
\hline
\end{tabular}

Fonte: Elaboração própria a partir dos resultados das simulações com o modelo IMAGEM-B.

${ }^{*}$ Como a escolha dos setores para os choques de produtividade é ad hoc, podendo gerar discordâncias, deixou-se em separado os resultados de investimentos em Infraestrutura urbana e mobilidade.

É importante destacar que, diante da estrutura do modelo (equações linearizadas), o resultado total para qualquer variável pode ser obtido a partir das somas dos resultados das sete simulações. Os resultados são apresentados na forma de taxas de variação percentual. Os números obtidos refletem a variação em relação a uma trajetória tendencial da economia, representando apenas o efeito adicional do referido investimento. Isto equivale a dizer que os resultados das simulações representam os impactos potenciais se todos os investimentos acima forem feitos. Os impactos da Copa-2014 devem ser interpretados de forma relativa, ou seja, representam variações em relação ao estado futuro da economia sem estes investimentos.

\section{Resultados das Simulações}

\subsection{Impactos Nacionais}

Feitas estas considerações e descritas as principais hipóteses envolvidas nas fases de construção e operação dos investimentos previstos para a Copa-2014, os impactos na economia brasileira variam de acordo com as suas fontes de recursos nas simulações de construção. De modo geral, conforme a Tabela 6, o consumo das famílias tem variação negativa quando o financiamento é considerado privado 
(Im3 e Im 4 - BNDES e Clubes de Futebol). O consumo do governo, por sua vez, financia os investimentos em $\operatorname{Im} 5$ (estádios). Nas demais simulações da fase de construção, o consumo do governo e das famílias não é impactado, conforme as hipóteses pressupostas nestes fechamentos. O PIB e o emprego crescem com os investimentos na fase de construção, a não ser na simulação com financiamento público ( $\operatorname{Im} 5)$, devido ao efeito negativo da queda do consumo do governo, que por pressuposição financia os investimentos na construção dos estádios. Observase que a queda do consumo do governo é acompanhada por uma variação negativa do emprego ( $\operatorname{Im} 5)$, visto que a administração pública é um setor intensivo em trabalho e que remunera parcela significativa da força de trabalho na economia.

O impacto estimado dos investimentos da Copa-2014 no Brasil é de elevação de $0,7 \%$ no PIB e $0,5 \%$ no emprego, relativamente a um cenário em que o evento não ocorresse. O efeito gerador dos investimentos é ligeiramente inferior a $1(0,92)$, uma vez que estes representam uma injeção de recursos de 0,75\% do PIB (ano base 2003). A queda nas exportações e a elevação das importações refletem as necessidades dos novos investimentos e a elevação dos custos de produção (crescimento do deflator do PIB e do índice de preços do consumo, IPC). Na fase de implementação, dessa forma, a balança comercial ajusta-se endogenamente, gerando um déficit marginal na balança comercial do país, ${ }^{6}$ dados os novos investimentos. Na simulação de operação (OP), por sua vez, o efeito positivo sobre o PIB reflete os ganhos de produtividade associados às melhorias da infraestrutura urbana.

6 No fechamento de operação, por sua vez, a balança comercial é exógena como proporção do PIB. 
TABELA 6 - Impactos da Copa-2014 no Brasil: Fases de Construção e Operação (Var. \%)

\begin{tabular}{|c|c|c|c|c|c|c|c|c|c|}
\hline \multirow{2}{*}{ Variável } & \multicolumn{7}{|c|}{ Implementação } & \multirow{2}{*}{$\frac{\text { Operação }}{\text { OP }}$} & \multirow{2}{*}{$\begin{array}{l}\text { Total } \\
\text { geral }\end{array}$} \\
\hline & $\operatorname{Im} 1$ & Im2 & Im3 & $\operatorname{Im} 4$ & $\operatorname{Im} 5$ & Im6 & Subtotal & & \\
\hline $\begin{array}{l}\text { Consumo das } \\
\text { Famílias }\end{array}$ & 0,000 & 0,000 & $-0,027$ & $-0,006$ & 0,000 & 0,000 & $-0,033$ & 0,437 & 0,405 \\
\hline Investimento & 0,535 & 0,235 & 0,187 & 0,042 & 0,719 & 2,431 & 4,149 & 0,417 & 4,565 \\
\hline $\begin{array}{c}\text { Consumo do } \\
\text { Governo }\end{array}$ & 0,000 & 0,000 & 0,000 & 0,000 & $-0,647$ & 0,000 & $-0,647$ & 0,437 & $-0,210$ \\
\hline Exportações & $-0,151$ & $-0,066$ & $-0,002$ & $-0,001$ & $-0,118$ & $-0,696$ & $-1,035$ & 0,245 & $-0,791$ \\
\hline Importações & 0,198 & 0,084 & 0,021 & 0,005 & 0,147 & 0,903 & 1,358 & 0,189 & 1,547 \\
\hline PIB real & 0,046 & 0,020 & 0,015 & 0,003 & $-0,038$ & 0,214 & 0,260 & 0,433 & 0,693 \\
\hline Emprego & 0,091 & 0,041 & 0,031 & 0,007 & $-0,111$ & 0,431 & 0,490 & 0,000 & 0,490 \\
\hline Deflator do PIB & 0,312 & 0,135 & 0,038 & 0,010 & 0,313 & 1,506 & 2,314 & $-0,122$ & 2,191 \\
\hline IPC & 0,117 & 0,051 & $-0,026$ & $-0,005$ & 0,062 & 0,531 & 0,729 & $-0,193$ & 0,536 \\
\hline $\begin{array}{l}\text { Preço das } \\
\text { Exportações }\end{array}$ & 0,134 & 0,057 & 0,002 & 0,001 & 0,105 & 0,620 & 0,919 & $-0,209$ & 0,709 \\
\hline
\end{tabular}

Fonte: Elaboração própria a partir dos resultados das simulações com o modelo IMAGEM-B ${ }^{*}$

\subsection{Impactos nos Estados e Cidades-Sede}

Nesta seção serão discutidos os impactos estaduais dos investimentos da Copa2014. A Tabela 7 apresenta os resultados agregados das 7 simulações (implementação e operação) em cada estado. Em todos os estados o impacto sobre o nível de atividade é positivo. Amazonas (AM), Rio Grande do Norte (RN), Ceará (CE) e Pernambuco (PE) são os Estados com maior impacto da Copa-2014, crescimento acima de $1,8 \%$ do PIB, relativo a um cenário em que os investimentos da Copa-2014 não ocorressem.

Os resultados estaduais estão relacionados com o tamanho do investimento em cada estado e também com relações de interdependência regional e estrutura produtiva de cada estado. Um exemplo é o impacto nos estados do Amazonas e Rio Grande do Norte, que devido ao tamanho relativo dos investimentos nesses estados (Tabela 2), mostram crescimento do PIB e do emprego mais significativos. O aumento de 4,6\% do PIB amazonense corresponde a uma injeção de $\mathrm{R} \$ 1,3$ bilhões na sua economia, ao passo que em Rio Grande do Norte o estímulo econômico atinge aproximadamente R \$ 606 milhões (4,5\% do PIB). Entretanto, levando-se em conta o tamanho relativo das economias dos 12 estados (PIB Regional em R\$), 26\% do efeito da Copa recai sobre São Paulo, 13,7\% sobre Minas Gerais, 13,5\% sobre o Amazonas, 9,6\% sobre o Rio de Janeiro, 8,7\% sobre a Bahia e 7,9\% sobre Pernambuco. Assim, os 
impactos dos investimentos da Copa-2014 concentram-se nos estados com estrutura produtiva mais complexa e integrada ao restante da economia brasileira.

TABELA 7 - Impactos da Copa-2014 nos Estados-Sede: Resultados Agregados das Simulações

\begin{tabular}{|c|c|c|c|c|c|c|c|c|c|c|c|c|c|}
\hline Variável & Unidade & $\mathrm{AM}$ & CE & RN & $\mathrm{PE}$ & $\mathrm{BA}$ & MG & RJ & SP & PR & RS & MT & DF \\
\hline Consumo das Famílias & Var. $\%$ & $-0,76$ & $-0,15$ & 5,13 & 0,55 & 0,88 & 0,79 & 0,18 & 0,38 & 0,53 & 0,26 & $-1,67$ & $-0,96$ \\
\hline Consumo do Governo & Var. $\%$ & $-3,65$ & $-1,73$ & 4,33 & $-0,61$ & $-0,22$ & $-0,26$ & $-0,15$ & $-0,06$ & $-0,25$ & $-0,12$ & $-2,45$ & $-0,83$ \\
\hline Exportações & Var. \% & $-0,25$ & $-0,60$ & $-0,74$ & $-0,86$ & $-0,79$ & $-0,96$ & $-0,78$ & $-0,84$ & $-0,70$ & $-0,80$ & 0,08 & $-0,02$ \\
\hline Importações & Var. $\%$ & 3,21 & 3,01 & 5,36 & 2,98 & 2,20 & 2,01 & 1,29 & 1,24 & 1,43 & 1,15 & 1,12 & 0,00 \\
\hline PIB real regional & Var. $\%$ & 4,60 & 2,05 & 4,52 & 1,85 & 1,16 & 0,93 & 0,50 & 0,51 & 0,51 & 0,24 & 1,08 & 0,11 \\
\hline PIB regional & $\begin{array}{l}\text { var. em R\$ } \\
\text { bilhões }\end{array}$ & 1,32 & 0,58 & 0,61 & 0,78 & 0,85 & 1,34 & 0,94 & 2,54 & 0,51 & 0,05 & 0,24 & 0,04 \\
\hline Emprego & Var. $\%$ & 1,07 & 0,73 & 2,93 & 0,86 & 1,00 & 0,92 & 0,26 & 0,41 & 0,66 & 0,33 & $-0,44$ & $-0,54$ \\
\hline Deflator do PIB & Var. \% & 1,84 & 3,63 & 3,20 & 3,27 & 2,96 & 3,35 & 1,62 & 1,71 & 2,45 & 1,72 & 0,75 & $-0,18$ \\
\hline IPC & Var. $\%$ & 0,41 & 0,72 & 0,89 & 0,70 & 0,84 & 0,79 & 0,31 & 0,42 & 0,67 & 0,50 & 0,09 & $-0,17$ \\
\hline Preço das Exportações & Var. \% & 0,29 & 0,57 & 0,54 & 0,76 & 0,75 & 0,64 & 0,67 & 0,73 & 0,65 & 0,72 & $-0,07$ & $-0,01$ \\
\hline $\begin{array}{l}\text { Arrecadação sobre } \\
\text { vendas }\end{array}$ & Var. $\%$ & 4,28 & 3,08 & 6,94 & 3,07 & 2,44 & 2,21 & 1,25 & 1,21 & 1,38 & 0,94 & 1,44 & 0,23 \\
\hline \multicolumn{2}{|c|}{ Arrecadação / Investimentos } & 0,11 & 0,12 & 0,14 & 0,14 & 0,21 & 0,31 & 0,14 & 0,27 & 0,35 & 0,35 & 0,04 & 0,01 \\
\hline
\end{tabular}

Fonte: Elaboração própria a partir dos resultados das simulações com o modelo IMAGEM-B •

O Gráfico 1 ilustra a relação entre o investimento da Copa-2014 e o impacto sobre o PIB em cada estado. Esta relação pode ser tomada como um efeito regional dos investimentos da Copa-2014, levando em conta todas as simulações efetuadas. Estes indicadores são influenciados tanto pelo tamanho dos investimentos em cada estado como pela estrutura produtiva de cada região e sua inserção na economia brasileira. Assim, Minas Gerais e São Paulo, com investimentos relativamente pequenos, têm maior impacto sobre sua economia tanto em decorrência da sua estrutura produtiva como do fato de captarem efeitos de vazamentos dos investimentos em outras cidades-sede. Comparativamente, Rio de Janeiro, Rio Grande do Sul e Mato Grosso parecem ter menor capacidade de internalização dos efeitos dos investimentos. Em termos gerais, o efeito dos investimentos da Copa-2014 é próximo de 1, ou seja, cada real investido gera cerca de 1 real de efeito econômico adicional. 


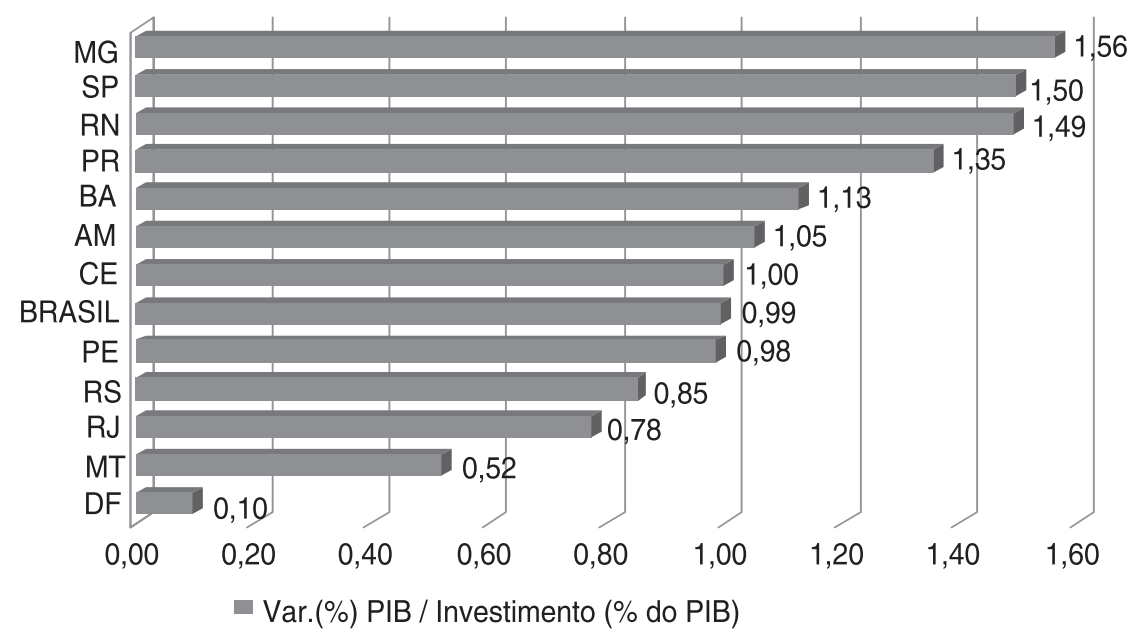

\section{GRÁFICO 1 - Efeito Gerador dos Investimentos da Copa 2014 (Relação Impacto/ Investimento)}

Fonte: Elaboração própria a partir dos resultados das simulações com o modelo IMAGEM-B.

Os resultados acima mostram que os impactos nos Estados-sede da Copa-2014 são relativamente homogêneos na direção: elevação do PIB, investimentos, queda das exportações, aumento da arrecadação de impostos. A queda das exportações e elevação das importações (que no modelo incluem os fluxos regionais e externos) reflete a elevação da atividade econômica nos Estados-sede, que em decorrência dos investimentos da Copa-2014 (fase de implementação especialmente), passam a demandar mais bens e serviços. Essa maior demanda reflete-se em elevação dos preços relativos dos estados e, consequentemente, em queda relativa das exportações. A Copa-2014 possui também impacto positivo sobre a arrecadação de impostos indiretos em cada estado, seguindo a elevação da atividade econômica.

A Tabela 7 mostra que a relação entre arrecadação de impostos sobre vendas e o volume de investimentos previstos em cada estado acompanha, em alguns casos, os resultados observados do Gráfico 1. Estados mais diversificados e integrados com o restante do Brasil, como São Paulo e Minas Gerais, mostram uma relação entre arrecadação e investimentos acima de 0,26 . Esse número significa que cada $\mathrm{R} \$ 1$ de investimento nos respectivos estados gera aproximadamente $R$ \$ 0,26 de arrecadação sobre as vendas. Este resultado deve ser lido com cautela, pois o efeito econômico projetado em cada estado não depende somente dos investimentos no estado, mas das relações de complementaridade e substituição entre as economias regionais. 
Os resultados que diferem entre os Estados-sede são as variações do consumo das famílias no Amazonas, Ceará, Mato Grosso e Distrito Federal (negativos) e as variações de emprego nestes dois últimos estados (negativos). O impacto negativo do consumo das famílias decorre das simulações de implementação em que os investimentos são financiados pelo consumo das famílias ( $\operatorname{Im} 3$ e $\operatorname{Im} 4)$. Nos estados acima, devido ao tamanho relativo deste componente no PIB dos estados, esse efeito negativo prevalece sobre o efeito positivo dos demais investimentos. ${ }^{7}$ Além disso, a queda do consumo do governo, decorrente dos investimentos financiados pelo governo (simulação Im5) repercute negativamente nas economias estaduais. Estes resultados devem ser lidos qualitativamente, no sentido de que em alguns estados os efeitos positivos dos investimentos da Copa 2014 podem ser esvaziados pela contração dos gastos do governo para seu financiamento.

A simulação de operação trabalha com aumentos de produtividade nas economias estaduais decorrentes dos investimentos, o que implica inicialmente menor necessidade de fatores primários (capital e trabalho) por unidade de produção. Em princípio, o efeito produtividade implica uma queda de emprego ou de utilização de fator trabalho, ${ }^{8}$ que tende a ser compensada pela elevação da atividade econômica. Como a Tabela 7 agrega também as simulações de implementação, em que o nível de atividade econômica impulsiona o emprego, o resultado líquido em geral é de elevação do emprego nos estados. No Amazonas, a estrutura produtiva industrial é significativa na economia do Estado, o que implica menor necessidade de emprego com a elevação de produtividade, resultado este inferior ao impacto positivo da fase de construção. No Distrito Federal e no Mato Grosso, pela elevada participação do consumo do governo no PIB, a simulação de financiamento público e de produtividade se sobrepõe aos demais impactos positivos.

Em termos intraestaduais, os resultados do módulo de decomposição do modelo (vide Anexo 2) podem ser explorados. ${ }^{9} \mathrm{O}$ cálculo da geração de emprego considera a variação percentual do emprego em cada cidade-sede ponderada pelo nível de emprego formal registrado em 2007 (RAIS). ${ }^{10}$ Nota-se que os municípios registram

7 Deve-se lembrar que o financiamento pelas famílias dos investimentos nas simulações $\operatorname{Im} 3$ e $\operatorname{Im} 4$ é feito na mesma taxa em todos os estados e não proporcionalmente aos investimentos em cada estado.

8 O modelo obtém as variações de utilização do fator trabalho, e não de emprego (pessoal ocupado). É possível que uma elevação na utilização de trabalho seja obtida pelo mesmo número de pessoal ocupado (via "horas-extras"), ou pelo aumento do pessoal ocupado (sem "horas-extras"). Assim, no primeiro caso o emprego não seria afetado, e no segundo a taxa de desemprego cairia. Neste trabalho, as variações de emprego devem ser entendidas como um "equivalente homenhora" de trabalho e não associadas diretamente a variações de pessoal ocupado (HADDAD e DOMINGUES, 2003).

9 O modelo gera resultados para todos os 5507 municípios brasileiros, mas apenas as sedes da Copa são tratadas neste trabalho.

10 É necessário ressaltar que os resultados provavelmente subestimam o efeito sobre o emprego, uma vez que os dados da RAIS consideram apenas o mercado formal de trabalho. 
um crescimento médio de $1,2 \%$ do PIB e do emprego, representando um acréscimo médio de $\mathrm{R} \$ 14,7$ bilhões nas economias municipais com o equivalente a $158 \mathrm{mil}$ empregos gerados.

Embora Natal apresente o maior impacto econômico (5,8\% do PIB), São Paulo é a cidade com o maior recurso injetado na sua economia (cerca de $\mathrm{R} \$ 3,3$ bilhões), gerando o equivalente a 41 mil empregos. Com menos destaque, projeta-se um impacto de 36 mil empregos na economia de Belo Horizonte, acompanhado por um aumento de 1,8\% do PIB. Haja vista que foi simulada a queda do consumo do governo para financiar a construção de estádios, municípios com grande participação da administração pública são os mais afetados por isso. Esse é caso de Brasília, onde a administração publica é o principal setor que remunera a força de trabalho na sua economia. Dessa forma, a queda do consumo do Governo retrai a atividade pública nessa cidade e, posteriormente, impacta negativamente o emprego.

TABELA 8 - Impacto da Copa 2014 de Emprego e Crescimento Econômico nas Cidades-Sede*

\begin{tabular}{lcccc}
\hline Municípios & PIB (var.\%) & $\begin{array}{c}\text { PIB (var. R\$ } \\
\text { milhões de 2003) }\end{array}$ & $\begin{array}{c}\text { Emprego } \\
\text { (var.\%) }\end{array}$ & $\begin{array}{c}\text { Emprego (ocupações } \\
\text { equivalentes) - mil }\end{array}$ \\
\hline Manaus (AM) & 5,87 & 2448,51 & 2,08 & 8,63 \\
Fortaleza (CE) & 3,66 & 1055,51 & 2,48 & 13,88 \\
Natal (RN) & 6,40 & 625,56 & 3,88 & 10,30 \\
Recife (PE) & 3,13 & 1337,64 & 2,37 & 12,74 \\
Salvador (BA) & 1,72 & 862,21 & 1,76 & 12,12 \\
Belo Horizonte (MG) & 1,87 & 2459,91 & 2,98 & 36,25 \\
Rio de Janeiro (RJ) & 0,58 & 1005,93 & 0,33 & 7,23 \\
São Paulo (SP) & 0,73 & 3363,41 & 0,98 & 41,06 \\
Curitiba (PR) & 0,99 & 779,22 & 1,86 & 13,73 \\
Porto Alegre (RS) & 0,41 & 376,61 & 0,87 & 5,66 \\
Cuiabá (MT) & 2,58 & 365,82 & 0,90 & 1,85 \\
Brasília (DF) & 0,11 & 58,20 & $-0,54$ & $-5,14$ \\
\hline Total & 1,25 & 14738,54 & 1,26 & 158,31 \\
\hline
\end{tabular}

Fonte: Elaboração própria a partir dos resultados das simulações com o modelo IMAGEM-B.

* Os resultados para as cidades-sede se baseiam nos resultados do módulo de decomposição top-down do modelo IMAGEM-B. 


\section{Considerações Finais}

Os resultados analisados neste trabalho dizem respeito aos impactos dos investimentos em infraestrutura urbana e estádios programados para a Copa-2014, anunciados pelo Ministério do Esporte no início de 2010. A literatura de economia dos esportes costuma elencar outros impactos advindos dos eventos esportivos, como por exemplo: ampliação dos setores de serviços e hotelaria; fluxo adicional de turistas no evento e pós-evento; e exposição internacional do país, com atração de investimento externo. Entretanto, tais impactos, se existem, são de difícil mensuração e projeção. Por exemplo, diversos especialistas em economia do turismo (e.g. MATHESON, 2002) consideram que um mega-evento como a Copa do Mundo apenas substitui turistas usuais no país-sede por "turistas-copa", e mesmo estes podem efetuar um dispêndio no país significativamente menor, tendo em vista os gastos com ingressos e deslocamentos para o evento.

Por fim, para responder à questão do título deste trabalho, "Quanto vale o show?", os principais resultados dos investimentos da Copa-2014 são a melhoria da infraestrutura urbana nas cidades-sede, o que representa efetivamente impacto de longo prazo na eficiência econômica de diversas cidades. Além disso, este trabalho destacou as opções de financiamento dos investimentos da Copa-2014, e sinalizou que o impacto econômico tende a diminuir com o financiamento público para as obras de estádios de futebol, uma vez que implicam ou no crescimento da dívida pública ou na redução do gasto das diferentes esferas de governo envolvidas. Embora no Brasil o futebol seja a "paixão nacional", não foi o foco deste trabalho avaliar o ganhos de longo prazo com a reforma e construção de estádios de futebol, apesar dos ganhos indiretos sobre a renda e o consumo das famílias estimados nas simulações apontarem o efeito positivo de bem-estar. Provavelmente, ganhos adicionais de bem-estar, e outros efeitos positivos intangíveis, ocorreriam com a vitória brasileira na Copa-2014.

\section{Referências}

ALMEIDA, E. S. D.; GUILHOTO, J. J. M. O Custo de Transporte como Barreira ao Comércio na Integração Econômica: O Caso do Nordeste. Revista Econômica do Nordeste, v. 38, n. 2, p. 224-243, abr.-jun., 2007.

ALMEIDA, E. S. Um modelo de equilíbrio geral aplicado espacial para planejamento e análise de políticas de transporte. 242 p., Tese (Doutorado em Economia) Faculdade de Economia, Administração e Contabilidade da Universidade de São Paulo (FEA/ USP), São Paulo, 2003.

BANCO NACIONAL DO DESENVOLVIMENTO ECONÔMICO E SOCIAL. Relatório da Administração - Sistema BNDES. Junho de 2009. Disponível em: 
http://www.bndes.gov.br/SiteBNDES/export/sites/default/bndes_pt/ Galerias/Arquivos/empresa/download/RelatAdm0609. pdf Acesso: 05 fev. de 2010.

BARCLAY, J. Predicting the costs and benefits of mega-sporting events: misjudgement of olympic proportions? Economic Affairs, v. 29, n. 2, p. 62-66, jun., 2009.

BASTOS, M; COBOS, P. Verba pública financiará 94\% dos estádios da Copa. Documento do Ministério do Esporte mostra que país vai gastar R \$ 5,3 bilhões. Folha de São Paulo. P. D1. fevereiro de 2010.

BRENKE, K.; WAGNER, G. G. The soccer world cup in Germany: a major sporting and cultural event - but without notable business cycle effects. DIW Berlin Weekly Report. v. 2, n. 3, p. 23-31, 2006.

CÂMARA MUNICIPAL DE BELO HORIZONTE (CMBH). Atuação do Legislativo. Luiz Ferreira faz balanço da CMBH em 2009. CMBH. Dezembro de 2009. Disponível em: http://www.cmbh.mg.gov.br/index.php?option=com_content \&task=view\&id=34875\&Itemid=199\&filter $=$ Acesso: 02 de fev. de 2010.

CAMPOS NETO, C.A.; SOUZA, F.H. (2011): Aeroportos no Brasil: investimentos recentes. perpectivas e preocupações. Nota Técnica 5, Diretoria de Estudos Setoriais, IPEA, Brasilia.

COATES, D; HUMPHREYS, B. The growth effects of sport franchises, stadia and arenas. Journal of Policy Analysis and Management, v. 18, n. 4, p. 601-624, 1999

DIXON, P. B.; PARMENTER, B. R.; SUTTON, J.; VINCENT, D. P. Orani, a Multisectoral Model of the Australian Economy. Amsterdam: North-Holland Pub. Co., 1982.

DIXON, P. B.; PARMENTER, B. R. Computable general equilibrium modeling for policy analysis and forecasting. In: H. M. AMMAN, D. A. KENDRICK, et al. (Ed.). Handbook of Computational Economics. Amsterdam: Elsevier, 1996.

DOMINGUES, E. P. Dimensão regional e setorial da integração brasileira na Área de Livre Comércio das Américas. 2002. 222 p. (Tese de Doutorado). Departamento de Economia/IPE, Universidade de São Paulo, São Paulo, 2002.

DOMINGUES, E. P.; HADDAD, E. A. política tributária e re-localização. Revista Brasileira de Economia, v. 57, n. 4, p. 515-537. oct.-dec., 2003.

DOMINGUES, E. P; MAGALHÃES, A. S.; FARIA, W. R. Infraestrutura, crescimento e desigualdade regional: uma projeção dos impactos dos investimentos do Programa de Aceleração do Crescimento (PAC) em Minas Gerais. Pesquisa e Planejamento Econômico, Rio de Janeiro, v. 39, n.1, p. 121-158, 2009.

FARIA, W. R; MAGALHÃES, A. S. Avaliação dos impactos regionais do projeto da rodovia BR-101: uma análise de equilíbrio geral computável. Anais do VI Encontro Nacional de Estudos Regionais e Urbanos. Aracaju, 2008.

GOLDEN GOAL SPORTS VENTURES LTDA (GOLDEN GOAL). Calculando o impacto econômico de mega-eventos esportivos. 2010. Disponível em: http:// 
www.goldengoal.com.br/br/downloads/Retorno_Jogos_Olimpicos.pdf. acesso: 05 fev. de 2010.

GUILHOTO, J. J. M.; SESSO FILHO, U. A. Estimação da matriz insumo-produto a partir de dados preliminares das contas nacionais. Economia Aplicada, v. 9, n. 2, abr.-jun., 2005.

HADDAD, E. A. Regional inequality and structural changes: lessons from the Brazilian experience. Aldershot: Ashgate, 209 p., 1999.

HADDAD, E. A. Retornos crescentes, custos de transporte e crescimento regional. 2004, 207 p. Tese (Livre-Docência em Economia) - Faculdade de Economia, Administração e Contabilidade daUniversidade de São Paulo (FEA/ USP), São Paulo, 2004.

HADDAD, E. A.; DOMINGUES, E. P. Projeções setoriais e regionais para a economia brasileira: 2001-2007, In: Mercado de trabalho no Brasil: padrões de comportamento e transformações institucionais. Ed.: CHAHAD, J. P. Z.; PICCHETTI, P. São Paulo: LTR Editora, p. 167-194, 487 p., 2003.

HADDAD, E.A.; HADDAD, P.R. Major sport events and regional development: the case of Rio de Janeiro 2016 Olympic Games. Regional Science Policy and Practice, v. 2, n.1, p. 79-95, jun. 2010. Disponível em: http://onlinelibrary.wiley. com/doi/10.1111/j.1757-7802.2010.01017.x/pdf . Acesso em: 29 nov. 2010.

HADDAD, E. A.; HEWINGS, G. J. D. Market imperfections in a spatial economy: some experimental results. The Quarterly Review of Economics and Finance, v. 45, n. 2-3, p. 476-496, mai., 2005.

HARRISON, W. J.; PEARSON, K. R. An introduction to GEMPACK. GEMPACK Document No. 1, Monash University, Clayton, Sixth edition, October 2002. Disponível em: . Acesso em: http://www.monash.edu.au/policy/gpdoc. htm 20 set. 2008.

HORRIDGE, M.; MADDEN, J.; WITTWER, G. The impact of the 2002-2003 drought on Australia. Journal of Policy Modeling, v. 27, n. 3, 2005, p. 285-308, abr. 2005.

LEONTIEF, W.; MORGAN, A.; POLENSKE, K.; SIMPSON, D.; TOWER, E. The economic impact--industrial and regional--of an arms cut. The Review of Economic Statistics. v.47, n. 3, p. 217-241, aug. 1965.

MADDEN, J. R. Economic and fiscal impacts of mega sporting events: a general equilibrium assessment. Public Finance and Management, v.6, n.3, p. 346-394, jan. 2006.

MAGALHÃES, A.S; DOMINGUES, E. P. Regional inequality and growth: the role of inter-regional trade in the Brazilian economy. Anais do XVII International Input-Output Conference. Universidade de São Paulo (USP), São Paulo, jul. 2009.

MATHESON, V. A. Upon further review: an examination of sporting event economic impact studies. The Sport Journal, v. 5, n. 1, 2002. 
MINISTÉRIO DO ESPORTE. Matriz de responsabilidades da Unidade Federativas. Ministério do Esporte. Janeiro de 2010. Disponível em: http://www.esporte. gov.br/assessoria EspecialFutebol/compromissosCopa2014.jsp. Acesso: 03 de fev. de 2010.

NOLL, R. G.; ZIMBALIST, A. Build the stadium - create the jobs. In: Noll, R.G.; Zimbalist, A. (Eds.) Sports, Jobs and Taxes: The Economic Impact of Sports Teams and Stadiums. Washington, DC: Brookings Institution Press., 540 p., 1997.

PEROBELLI, F. S. Análise das interações econômicas entre os estados brasileiros. 2004, 250 p. Tese (Doutorado em Economia). - Faculdade de Economia, Administração e Contabilidade da Universidade de São Paulo (FEA/ USP), São Paulo, 2004.

PILLAY, U.; BASS, O. Mega-events as a response to poverty reduction: the 2010 FIFA World Cup and its urban development implications. Urban Forum, v.9, n.3, p. 329-346, 2008.

PORTER, P. K. Mega-sports events as municipal investments: a critique of impact analysis. In: FIZEL, J.; GUSTAFSON, E.; HADLEY, L. (Eds.) Sports Economics: Current Research. Westport, CT: Praeger, 260 p., 1999.

SCHWESTER, R. W. An examination of the public good externalities of professional athletic venues: justifications for public financing? Public Budgeting \& Finance, v.27, n. 3, p. 89-109, 2007.

SECRETARIA DA COMUNICAÇÃO SOCIAL DA PRESIDÊNCIA DA REPÚBLICA. Impacto econômico das Olimpíadas no Rio será de US\$14 bilhões. Ipcdigital.com. outubro de 2009. Disponível em: http://www.ipcdigital.com/ br/Noticias/Brasil/Impacto-economico-das-Olimpiadas-no-Rio-sera-de-US-14 -bilhoes, Acesso: 02 de fev. de 2010.

SWINNEN, J.; VANDEMOORTELE, T. Sports and development: an economic perspective on the impact of the 2010 World Cup in South Africa. ICSSPE Bulletin, v.53, p.1-6, 2008.

VASCONCELOS, J. R. D.; OLIVEIRA, M. A. D. Análise da matriz por atividade econômica do comércio interestadual no Brasil - 1999. Rio de Janeiro: IPEA (Texto para discussão n. 1159), 2006. 


\section{ANEXO 1: Principais Fontes na Composição do funding do BNDES ( $1^{\circ}$ semestre 2009)}

\begin{tabular}{|c|c|c|c|}
\hline esc & & art. $(\%)$ & \\
\hline $\mathrm{AT}$ & & & \\
\hline \multicolumn{4}{|c|}{$\begin{array}{l}\text { Apesar deste fundo não receber mais contribuições desde 1988, devido à realocação dos recursos para o FAT, o sald } \\
\text { desta rubrica no passivo ainda apresenta crescimento a cada ano. Isto porquê a remuneração das operações } \\
\text { financiadas com os recursos devoluções do PIS-PASEP têm sido superiores às retiradas dos beneficiários deste } \\
\text { fundo, ou seja, das do BNDES ao Fundo PIS-PASEP. }\end{array}$} \\
\hline mpréstimos locais (principalmente Tesouro Nacional) & & 32,44 & \\
\hline \multicolumn{4}{|l|}{$\begin{array}{l}\text { Em função da Lei n }{ }^{\circ} 11.948 / 09 \text { que autorizou a concessão de c } \\
\text { se destacando no funding do banco. }\end{array}$} \\
\hline rincip & & 0,74 & \\
\hline \multicolumn{4}{|c|}{$\begin{array}{l}\text { Banco Japonês de Cooperação Internacional (JBIC), China Development Bank (CDB), Banco de Crédito Alemão } \\
\text { para Reconstrução Econômica (KfW), Banco Nórdico de Investimento (NIB), Banco Mundial (BIRD) e Banco Inter- } \\
\text { Americano de Desenvolvimento (BID). }\end{array}$} \\
\hline Outras Fontes de recursos & 27173 & 10,33 & Privado \\
\hline \multicolumn{4}{|c|}{$\begin{array}{l}\text { Administração do Fundo da Marinha Mercante (FMM) e do Fundo Nacional de Desenvolvimento (FND); Emissão } \\
\text { de Captações no Mercado, através de operações compromissadas com o Banco do Brasil utilizando parte dos títulos } \\
\text { públicos adquiridos junto ao TN; e captação através de Depósitos Interfinanceiros, junto a instituições financeiras } \\
\text { privadas nacionais. }\end{array}$} \\
\hline & & & \\
\hline
\end{tabular}

Fonte: BNDES (2009).

\section{ANEXO 2 - Modelo de Equilíbrio Geral Computável Multi-Regional}

Neste trabalho utilizou-se o modelo denominado IMAGEM-B (Integrated Multiregional Applied General Equilibrium Model - Brazil), devido à especificação multirregional integrada: é um modelo bottom-up para os 27 estados e top-down para as 558 microrregiões ou para os 5507 municípios do Brasil. Na especificação bottomup, o comportamento dos agentes é modelado a nível estadual (regiões endógenas) e, neste sentido, os resultados nacionais são agregações dos resultados estaduais. A especificação top-down para municipais permite uma decomposição consistente dos resultados estaduais nesse nível de regionalização. ${ }^{11}$ Outra característica específica do modelo IMAGEM-B é a capacidade de lidar com margens de transporte e comercialização diferenciadas regionalmente.

O IMAGEM-B é um modelo do tipo Johansen, no qual a estrutura matemática é representada por um conjunto de equações linearizadas e as soluções são obtidas na forma de taxas de crescimento. Seu módulo bottom-up segue a estrutura teórica do modelo TERM (HORRIDGE et alii, 2005). Destacam-se, na sua estrutura, a presença de firmas (inclusive investidores) minimizadoras de custos e de famílias maximizadoras de utilidade; a determinação, de forma residual, do consumo

11 A especificação dessa decomposição top-down segue o modelo delineado em Leontief et alii (1965) e implementado em Dixon et alii (1982) no modelo Orani. 
privado e o ajustamento da poupança ao investimento, sendo este último fixado exogenamente.

No Brasil existem vários modelos como, por exemplo, o modelo B-MARIA (HADDAD, 1999), que foi o primeiro modelo EGC multirregional para o país, desenvolvido a partir do modelo Monash-MRF (ADAMS et alii 2000).

A partir do modelo B-MARIA derivam os modelos SPARTA (DOMINGUES, 2002) e B-MARIA-27 (PEROBELLI, 2004). ${ }^{12}$

O modelo também assume que todos os usuários numa região em particular, de bens industriais, por exemplo, utilizam-se como origem às demais regiões em proporções fixas. Assim, a necessidade de dados de origem por usos específicos no destino é eliminada. No caso brasileiro, por exemplo, existem matrizes de comércio interestadual por setores (VASCONCELOS e OLIVEIRA, 2006), mas não a informação sobre a destinação por uso nas regiões compradoras. Esta informação foi utilizada para calibrar as matrizes de comércio do IMAGEM-B, ${ }^{13}$ o que o distingue das versões do TERM calibradas para outros países.

No modelo IMAGEM-B, num ambiente de estática comparativa, as famílias, setores e investidores escolhem entre produtos ou insumos domésticos e importados (de outro país) por uma especificação CES (hipótese de Armington), baseada no preço de compra. Os setores produzem em retornos constantes de escala e utilizam, além dos insumos, fatores primários de produção: trabalho, capital e terra. Por outro lado, as equações de demanda das famílias estão especificadas por preferências CES/ Klein-Rubin, de forma que primeiramente elas escolhem entre produtos domésticos e importados por uma CES e, em seguida, sua utilidade é maximizada por uma agregação Klein-Rubin dos bens compostos. Por fim, os “investidores”, para produzir capital, escolhem entre insumos domésticos e importados por uma especificação CES e o seu conjunto dos insumos intermediários compostos é formado pela combinação em proporções fixas (Leontief).

Há equilíbrio de mercado para todos os bens, tanto domésticos como importados, assim como no mercado de fatores (capital e trabalho) em cada região. As demandas por margens (transporte e de comércio) são proporcionais aos fluxos de bens aos quais as margens estão conectadas. Os preços de compra para cada um dos grupos de uso em cada região (produtores, investidores, famílias, exportadores, e governo)

12 Como por exemplo, Haddad e Hewings (2005), Haddad e Domingues (2003) e Domingues e Haddad (2003).

13 O modelo já foi utilizado em alguns trabalhos, como na análise dos impactos de investimentos em infraestrutura(DOMINGUES et alii, 2009), transportes (FARIA e MAGALHÃES, 2008), e na análise de comércio inter-regional brasileiro (MAGALHÂES e DOMINGUES, 2009). 
são a soma dos valores básicos, impostos (diretos e indiretos) sobre vendas e margens (de comércio e transporte).

Os dados utilizados na calibragem da extensão top-down municipal foram as participações de cada município nos setores do modelo, obtidas a partir das informações do PIB municipal e de emprego. ${ }^{14}$ Portanto, o módulo requer uma matriz de dimensão 5507 x 36, representando a participação de cada município nos 36 setores do modelo. Uma matriz de mapeamento 5507 X 27, dos municípios para os estados, também foi necessária para relacionar o município ao respectivo estado.

O módulo municipal é uma extensão ao conjunto de equações do modelo bottom-up, que decompõe os resultados estaduais para municipais que constituem cada unidade da federação. A especificação teórica do módulo municipal segue a extensão ORES do modelo ORANI (DIXON et alii, 1982). Esse sistema de equações parte da classificação dos setores em duas categorias: "municipal" e "estadual". Um setor "municipal" é aquele cuja dinâmica (crescimento) no município segue as variações da demanda local (municipal). Um setor "estadual" cresce na mesma taxa em todos os municípios do respectivo Estado, de forma que sua dinâmica está conectada ao nível de atividade do setor estadual. Neste caso, não há alteração da participação do setor municipal na economia do estado. Formalmente, para setores "estaduais" a decomposição top-down processa-se assumindo que a variação percentual da produção (e também no emprego) do setor $j$ no município $r, x(j, r)$, é igual à mudança percentual do setor estadual, $x(j)$, isto é:

$$
x(j, r)=x(j) \forall \text { municípios num Estado }
$$

Sujeita à restrição:

$$
\sum S(j, r) x(j, r)=x(j) \forall \text { os setores estaduais }
$$

na qual $S(j, r)$ representa a parcela da região $r$ na produção nacional do setor $j$. Assim garante-se que a soma ponderada das variações setoriais municipais seja igual à variação do setor estadual.

Para os setores denominados "municipais", a decomposição baseia-se na variação da demanda no município, calculada via participação dos municípios no consumo

14 O PIB municipal para quatro grandes setores (Agropecuária, Indústria, Serviços e Administração pública) foi obtido diretamente das informações disponibilizadas pelo IBGE. Os dados da RAIS para massa salarial, por município, permitiram desagregar Indústria e Serviços nos demais 34 setores do modelo. 
das famílias. Assim, apenas o comportamento do consumo das famílias é distinto entre os municípios de um Estado. Logo, o efeito diferencial na demanda local, que gera a alteração na demanda dos setores "municipais", não é influenciado por outros componentes da demanda final (investimento, gastos do governo e exportações).

Formalmente, tem-se:

$$
x(j, r)=y(r) \forall \text { os setores "municipais" }
$$

em que $y(r)$ representa a mudança percentual da demanda do município $r$.

Desta forma, no caso dos setores definidos como "municipais", há alteração da participação do setor na economia do estado, gerando um efeito multiplicador diferenciado no território. Sete setores foram definidos como "municipais": água e saneamento, construção civil, comércio, serviços prestados às famílias, serviços prestados às empresas, aluguel de imóveis e serviços privados não mercantis. Os demais 29 setores são definidos como "estaduais".

A apresentação esquemática das soluções de Johansen para modelos EGC é padrão na literatura. A seguir é apresentado um resumo desse procedimento de forma a se obter uma visão de como o modelo é operacionalizado. Maiores detalhes podem ser encontrados em Dixon et alii (1982) e Dixon e Parmenter (1996). Esta apresentação segue a desenvolvida em Domingues (2002).

O sistema de equações do modelo IMAGEM-B pode ser escrito como:

$$
F(V)=0
$$

onde $\mathrm{V}$ é um vetor de equilíbrio de dimensão $n$ (número de variáveis), e $F$ é uma função-vetor não linear de dimensão $m$ (número de equações). Supõe-se que $F$ seja diferenciável, e que o número de variáveis seja maior que o número de equações no sistema $(n>m)$. Dessa forma, $(n-m)$ variáveis devem ser determinadas exogenamente. Uma solução inicial de equilíbrio, $\mathrm{V}^{* *}$, deve ser determinada para fins de calibragem, ou seja, supõe-se que:

$$
\exists \mathbf{V}=\mathbf{V}^{*} \text { tal que } F\left(\mathbf{V}^{*}\right)=\mathbf{0}
$$

Dada a solução inicial, $\mathrm{V}^{*}$, um novo conjunto de soluções pode ser obtido para um dado vetor de alterações nas variáveis exógenas. Dessa forma, para se computar o novo conjunto de soluções para o modelo é necessária a partição do vetor $V$ em dois grupos de variáveis, endógenas e exógenas. Seja Y o vetor contendo as $m$ variáveis 
endógenas e $\mathrm{X}$ o vetor contendo as $(n-m)$ variáveis exógenas. A equação (4) pode ser reescrita como:

$$
\mathbf{F}(\mathbf{Y}, \mathbf{X})=\mathbf{0}
$$

O problema é computar Y para um dado X, sendo que não é possível, normalmente, escrever Y como uma função explícita de X. Várias técnicas podem ser empregadas para computar Y. A solução por linearização assume que já se possui alguma solução para o sistema $\left(\mathrm{Y}^{0}, \mathrm{X}^{0}\right)$, tal que:

$$
\mathbf{F}\left(\mathbf{Y}^{0}, \mathbf{X}^{0}\right)=\mathbf{0}
$$

Em geral a solução inicial é obtida dos dados do período base em que o modelo é calibrado, ou seja, assume-se que o sistema é válido para algum ponto no passado. Para pequenas alterações em $\mathrm{dX}$ e dY, e sob hipóteses convencionais para o comportamento da função $F$, a diferenciação total de (7) permite obter: ${ }^{15}$

$$
F_{Y}(Y, X) d Y+F_{X}(Y, X) d X=0
$$

onde $F_{Y}$ e $F_{X}$ são matrizes de derivadas parciais de $F$ avaliadas em $\left(Y^{0}, X^{0}\right)$. Para que as soluções sejam obtidas na forma de taxas de variação é conveniente expressar dY e dX como pequenas variações percentuais $\mathrm{x}$ e y. Portanto, um típico elemento dos vetores $\mathrm{x}$ e y são definidos como:

$$
y=100 \mathrm{dY} / \mathrm{Y} \quad \text { e } \quad x=100 \mathrm{dX} / \mathrm{X}
$$

Da mesma forma podem ser definidas as seguintes funções:

$$
\mathbf{G}_{\mathbf{Y}}(\mathbf{Y}, \mathbf{X})=\mathbf{F}_{\mathbf{Y}}(\mathbf{Y}, \mathbf{X}) \hat{\mathbf{Y}} \quad \text { e } \quad \mathbf{G}_{\mathbf{X}}(\mathbf{Y}, \mathbf{X})=\mathbf{F}_{\mathbf{X}}(\mathbf{Y}, \mathbf{X}) \hat{\mathbf{X}}
$$

onde $\hat{\mathbf{Y}}$ e $\hat{\mathbf{X}}$ são matrizes diagonais. Assim o sistema linearizado torna-se:

$$
\mathbf{G}_{\mathbf{Y}}(\mathbf{Y}, \mathbf{X}) \mathbf{y}+\mathbf{G}_{\mathbf{X}}(\mathbf{Y}, \mathbf{X}) \mathbf{x}=\mathbf{0}
$$

Soluções para sistemas como (11) podem ser facilmente computadas por meio de técnicas de álgebra linear. Estas representam, entretanto, apenas uma solução

15 As hipóteses usuais são de continuidade e diferenciabilidade de $F$ e solução única. Em geral estas características são atendidas em sistemas walrasianos de equilíbrio geral expressos na forma de equações linearizadas. 
acurada para pequenas mudanças em X e Y. Caso contrário, erros de linearização podem ocorrer. A aproximação linear, ou em primeira ordem, da solução de (11) é dada por:

$$
\mathbf{y}=-\mathbf{G}_{\mathbf{Y}}(\mathbf{Y}, \mathbf{X})^{-1} \mathbf{G}_{\mathbf{X}}(\mathbf{Y}, \mathbf{X}) \mathbf{x}
$$

A equação (12) leva à solução de Johansen, $\mathrm{Y}^{\mathrm{J}}$, uma aproximação da solução verdadeira, Yexata . Essa observação leva à ideia de "particionar" as alterações em X em pequenos passos, e para cada subalteração em $\mathrm{X}$ usar a aproximação linear para derivar a sub-resposta de Y. A partir dos novos valores de $\mathrm{X}$ e $\mathrm{Y}$ as matrizes de coeficientes $G_{Y}$ e $G_{X}$ são recomputadas e o processo é repetido para cada passo. Esta técnica é conhecida como método de Euler, uma das mais simples opções em técnicas de integração numérica - processo de uso de equações diferenciais para se mover de uma solução para outra. Para uma aproximação em 3 passos, o erro de linearização é sensivelmente menor, aproximando-se da solução exata. Quanto maior o número de passos, melhor a aproximação.

Os modelos EGC são operacionalizados no programa GEMPACK. ${ }^{16}$ Além do método de Euler, é possível obter as soluções por dois métodos alternativos, Gragg e Midpoint. Estes métodos são variações do método de Euler e podem, em alguns casos, produzir resultados mais precisos para um mesmo número de passos. No caso do IMAGEM-B, um procedimento de cálculo em vários estágios (JOHANSEN/ EULER) é utilizado, em que o vetor de choques exógenos é dividido em $p$ partes iguais. Desta forma, pode-se definir uma sequência de cálculos, de modo que as matrizes $G_{Y}$ e $G_{X}$ sejam reestimadas em cada estágio. A questão teórica que se coloca diz respeito à maneira em que a solução do modelo converge para a solução "verdadeira" à medida que $p$ cresça e, caso convirja, ao número de estágios (tamanho de $p$ ) necessário para se obter uma solução precisa do modelo. Dixon et al. (1982) demonstram que quando $p$ tender a infinito, o método de vários estágios de Johansen/Euler produzirá uma solução exata do modelo.

16 O modelo foi utilizado na versão 10.0 do programa GEMPACK. Sobre sua utilização na implementação de modelos EGC, ver Harrison e Pearson (2002). 